\title{
Effects of cognitive interference on biofeedback learning
}

\author{
PAUL W. FOOS \\ University of North Carolina, Charlotte, North Carolina \\ BENJAMIN ALGAZE \\ Psychological Affiliates of Miami, Miami, Florida \\ and \\ GEORGE KALLAS \\ Florida International University, Miami, Florida
}

\begin{abstract}
Students learned to raise the skin temperature of their hands while performing no other task or one of two other tasks simultaneously. Other tasks involved checking to see whether a presented word contained the letter $\mathrm{E}$ or mentally adding two two-digit numbers. Only mental addition interfered with biofeedback learning. These results support a cognitive information-processing view of biofeedback learning and not a traditional reinforcement view. Suggestions are made for trainers and learners.
\end{abstract}

In biofeedback training, an individual who is given information about bodily changes (e.g., in muscle tension, skin temperature, heart rate) attempts to modify those changes. People are generally quite successful at learning how to do this, and biofeedback has become a valuable tool in the treatment of many psychosomatic disorders (Green \& Green, 1977; Wentworth-Rohr, 1984). There are, however, conflicting views on how biofeedback works and on what the best approach in training might be. These views are briefly described below and tested in two simple experiments.

The reinforcement view is based on a behavioral analysis of biofeedback training. Quite simply, the reason that individuals are able to gain some control over bodily changes is that they are reinforced for doing so. For example, the response of increasing blood flow to the hands to produce warmer hands is reinforced by the visual and/or auditory signal that indicates success; success is reinforcing. Because the response has been reinforced, it will tend to be repeated. The individual need only be aware of a response-reinforcement contingency. In training, it is thus important to provide a strong and appropriate reinforcement and to use techniques (e.g., a variable ratio schedule) that will maintain the learned response in the future.

The cognitive view is based on an information-processing analysis of biofeedback training. In learning how to warm the hands, the individual tries a number of different mental strategies, such as rehearsing a phrase (e.g., "warmer hands") or focusing on an image (e.g., of hands on a warm stove). Rather than serve as a reinforcer, the visual and/or auditory signal provides information that enables

Correspondence should be addressed to Paul W. Foos, Department of Psychology, University of North Carolina, Charlotte, NC 28223. the learner to select the most effective mental strategy. Considerable cognitive effort is required. In training, it is thus important to suggest different strategies that others have found effective.

In the following experiments, all participants were trained to alter the skin temperature of their hands. Such training has been shown to be an effective treatment for headache (see, e.g., Blanchard, Andrasick, Evans, Neff, \& Appelbaum, 1985). In the first experiment, some participants raised their hand temperatures while others lowered their hand temperatures; in the second experiment, all participants tried both tasks.

So that the reinforcement and cognitive views could be compared, participants in each experiment were asked to learn while also performing another task and while not performing another task. These other tasks demanded different levels of processing (see Craik \& Lockhart, 1972) and, thus, different amounts of cognitive effort. For example, one task involved determining whether or not a presented word contained the letter $\mathrm{E}$, a task that requires very little cognitive effort. The other task, which involved the mental addition of two two-digit numbers, required much more cognitive effort. If biofeedback learning also requires considerable cognitive effort, mental addition should interfere with this learning to a much greater extent than would checking words for the letter E. If biofeedback learning occurs through reinforcement, with little (or no) cognitive effort, neither task should produce much interference.

\section{METHOD}

\section{Participants}

The subjects in both experiments were undergraduate students at Florida International University who participated to fulfill a course requirement and/or to earn extra credit. In the first experiment, 5 ran- 
domly assigned students learned to raise hand temperature while another 5 tried to lower hand temperature. In the second experiment, 14 participants tried to raise and lower their hand temperatures.

\section{Materials}

For the E checking task, all words were high-frequency (Kucera \& Francis, 1967) and were printed on index cards for presentation. For the mental addition task, two randomly selected two-digit numbers were printed on each index card, separated by a plus sign.

\section{Apparatus}

All participants learned to alter hand temperature by using the Cyborg Biolab 21 System and received visual (i.e., a moving bar on a television monitor) and auditory (i.e., a tone that changed pitch) feedback. A thermal probe was taped to the forefinger of the nondominant hand, which rested in the participant's lap during training.

\section{Procedure}

In both experiments, all participants tried to alter hand temperature under three different conditions. On a third of the 5-min trials, they altered temperature and performed no other task. On another third, they altered temperature while also checking presented words for the letter $\mathrm{E}$ and responded verbally (i.e., "yes" or "no"). On another third, they altered temperature while performing mental addition and responded verbally.

The order in which these three learning sessions were presented was incompletely counterbalanced across three blocks of trials for all participants in the first experiment, producing a total of nine trials (i.e., three for each condition, which occurred once in each of three blocks). In the second experiment, all received the same incomplete counterbalancing across blocks for nine trials followed by a second nine trials. Half received nine trials of raising temperature first followed by nine of lowering temperature; the other half received nine of lowering followed by nine of raising. In both experiments, baseline temperatures were recorded before each trial. Data consisted of the change from baseline recorded on each trial.

\section{RESULTS AND DISCUSSION}

Table 1 shows the mean temperature change from baseline for temperature raising under all conditions for both experiments. Participants were unable to significantly lower their temperatures from baseline in any of the conditions in either experiment.

In the first experiment, participants were able to significantly raise their hand temperatures except when performing mental addition $[F(1,16)=4.39, p<.05]$. This finding was replicated in the second experiment $[F(1,234)$ $=5.16, p<.05]$. These results support the cognitive information-processing view of biofeedback learning. When cognitive effort is directed to another demanding
Table 1

Mean Temperature Change for Each Condition in Each Experiment

\begin{tabular}{lcc}
\hline & \multicolumn{2}{c}{ Experiment } \\
\cline { 2 - 3 } Additional Task & 1 & 2 \\
\hline None & 1.08 & .79 \\
E Checking & 1.79 & .95 \\
Addition & .16 & -.12 \\
\hline
\end{tabular}

Note-Means are reported in degrees Fahrenheit. Only means for temperature raising are shown.

task, such as mental addition, no biofeedback learning takes place.

These results have two important implications for biofeedback trainers and learners. First, one must be able to devote cognitive effort to biofeedback and not elsewhere if learning is to occur. Thus, the learning environment should be free of distractions to aid the learner in focusing on the learning task. The learner should try to clear her/his mind from other activities while learning to perform. In many cases, this may require the trainer to thoroughly relax the learner before beginning training.

Second, successful mental strategies should be suggested to the learner, because this may speed the learning process. Trainers should make themselves aware of the strategies that other clients have used successfully. In the present experiments, participants reported success with a number of imagery strategies such as picturing hands over a fire or in an oven. One very successful participant said that she imagined pushing the blood into her hands to make them warm. Such strategies may be good starting places for new learners.

\section{REFERENCES}

Blanchard, E. B., Andrasick, F., Evans, D. D., NefF, D. F., \& APPELBAUM, K. A. (1985). Individual predictors of self-regulating treatment outcome in tension headache. Paper presented at the annual meeting of the Biofeedback Society of America, New Orleans.

Craik, F. I. M., \& LockHART, R. S. (1972). Levels of processing: A framework for memory research. Journal of Verbal Learning \& Verbal Behavior, 11, 671-684.

GreEN, E., \& Green, A. (1977). Beyond biofeedback. New York: Dell Publishing.

KUČERA, H., \& FrANCIS, W. N. (1967). Computational analysis of presentday American English. Providence, RI: Brown University Press.

WENTWORTH-ROHR, I. (1984). Symptom reduction through clinical biofeedback. New York: Human Sciences Press.

(Manuscript received September 19, 1991.) 